facilitate facial EMG monitoring. This might have enhanced the compression of the submandibular gland and the encompassing tissues. The use of bite block throughout surgery may additionally be a predisposing factor. Therefore, it is recommended to secure the endotracheal tube on the ipsilateral side of the surgery to reduce tissue compression.

Acute sialadenitis following anesthesia is a rare complication that should be considered as one of the etiologies in patients presenting with acute postoperative respiratory distress, especially following surgeries in the park bench position. In a threatened airway scenario caused by sialadenitis, securing the airway could be difficult. Emergency tracheostomy is the next feasible option, which could be challenging due to the distorted anatomical landmarks owing to the neck swelling.

\section{Conflict of Interest}

None declared.

\section{References}

1 Uchino $\mathrm{H}$, Motegi $\mathrm{H}$, Kobayashi $\mathrm{H}$, et al. Postoperative acute submandibular sialadenitis after neurosurgery: two case reports and a review of the literature. NMC Case Rep J 2015;3(1):1-4

2 Kim LJ, Klopfenstein JD, Feiz-Erfan I, Zubay GP, Spetzler RF. Postoperative acute sialadenitis after skull base surgery. Skull Base 2008;18(2):129-134

3 Singha SK, Chatterjee N. Postoperative sialadenitis following retromastoid suboccipital craniectomy for posterior fossa tumor. J Anesth 2009;23(4):591-593

4 Shimizu S, Sato K, Mabuchi I, et al. Brachial plexopathy due to massive swelling of the neck associated with craniotomy in the park bench position. Surg Neurol 2009;71(4):504-508

5 Hamaguchi T, Suzuki N, Kondo I. A case of anesthesia mumps that required postoperative re-intubation. JA Clin Rep 2018;4(1):22-25

6 Fujisawa Y, Aiyama S. Histochemical and chronological analysis of mouse submandibular gland parenchyma subjected to abrupt reperfusion. Histol Histopathol 2003;18(3):871-878

\title{
Using Smartphone Application to Guide the Angulation of Head End of Patient Bed
}

\author{
Summit D. Bloria ${ }^{1} \quad$ Pallavi Bloria ${ }^{2} \quad$ Rajeev Chauhan ${ }^{1}$ \\ ${ }^{1}$ Department of Anesthesia and Intensive Care, Postgraduate \\ Institute of Medical Education and Research, Chandigarh, India \\ 2Department of Anaesthesia, Government Medical College, Jammu, \\ Jammu and Kashmir, India
}

J Neuroanaesthesiol Crit Care 2021;8:226-227.

Traditionally, neurological patients have been nursed in intensive care units (ICUs) and hospital wards with head end elevated at 30 to 45 degrees. Also, in mechanically ventilated patients, elevation of head end of the patient bed at 45 degrees has been proven to significantly reduce the incidence of aspiration and ventilator-associated pneumonia (VAP). ${ }^{1}$ Indeed, ensuring head end elevation of at least 30 degrees is a part of almost all proposed VAP bundles that have documented lower VAP rates. ${ }^{2}$ However, it has been seen that the application of this simple intervention remains low. ${ }^{3}$ Reeve and Cook

\begin{abstract}
Address for correspondence Summit Dev Bloria, MD, DM, Department of Anesthesia and Intensive Care, Postgraduate Institute of Medical Education and Research, Chandigarh 160012, India (e-mail: summitbloria13@gmail.com).
\end{abstract}

found that majority of mechanically ventilated patients were kept with angle of the bed elevated less than 30 degrees. ${ }^{4}$

We believe that part of this low implementation is due to lack of knowledge, hospital practices, etc. While some ICU beds have a mechanical indicator (a small bead that moves along a scale on the side rail of the bed), in many ICUs and in hospital wards, the beds may not have any indicator of angle of head end elevation. Also, in the present coronavirus disease 2019 times with many newly established ICUs, ICU beds with angulation indicators may not be available. published online

October 16, 2020
DOI https://doi.org/

$10.1055 / \mathrm{s}-0040-1717831$

ISSN 2348-0548. (c) 2020. Indian Society of Neuroanaesthesiology and Critical Care.

This is an open access article published by Thieme under the terms of the Creative Commons Attribution-NonDerivative-NonCommercial-License, permitting copying and reproduction so long as the original work is given appropriate credit. Contents may not be used for commercial purposes, or adapted, remixed, transformed or built upon. (https://creativecommons.org/licenses/by-nc-nd/4.0/).

Thieme Medical and Scientific Publishers Pvt. Ltd. A-12, 2nd Floor, Sector 2, Noida-201301 UP, India 


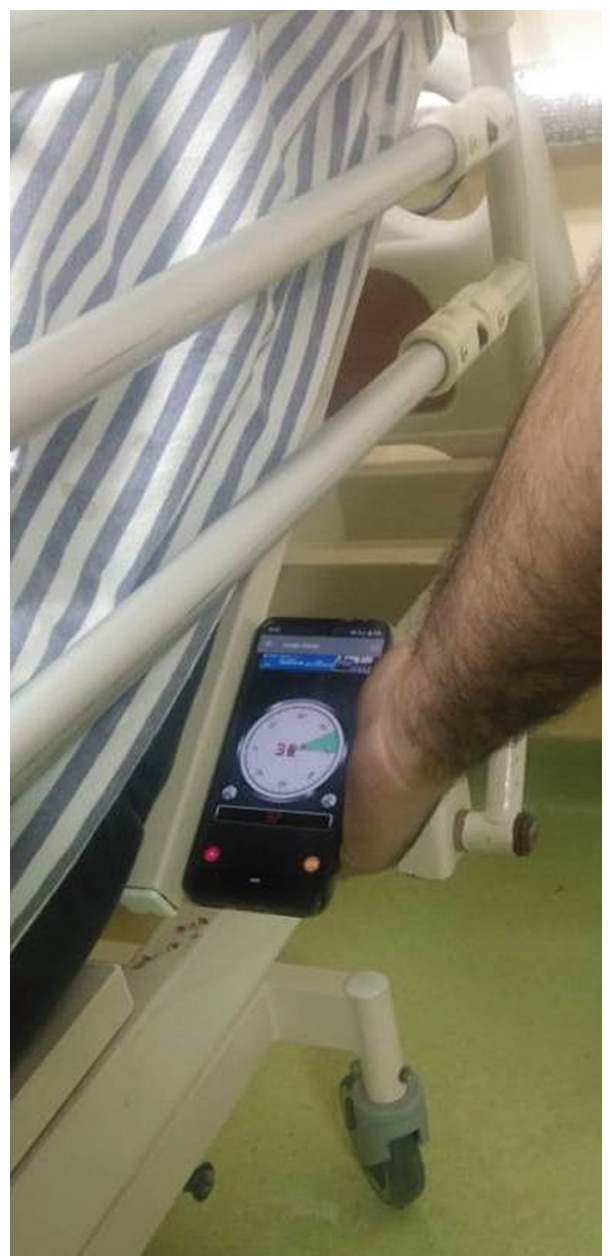

Fig. 1 Mobile phone aligned parallel to head end of bed to determine the angulation of head end of bed.

In such a scenario, one can use a free mobile application (Angle Meter, Smart Tool Factory, Istanbul, Turkey-available free on Google Play Store). This free app allows measurement of the angle of inclination of mobile phone. By simply tilting the mobile phone parallel to the head end of the ICU bed, the angle of head end elevation of bed can be determined (-Figs. 1 and 2). Using this app, one can ensure head end elevation of more than 30 degrees in ICU patients. This application can be utilized in places where ICU beds do not have head end elevation indicators. Presently, there is paucity of conclusive evidence suggesting the accuracy of these applications when used for this purpose, although mobile applications are increasingly finding applications inside hospitals and ICUs. We conducted a study to determine this accuracy of the application using an ICU bed with a mechanical angle indicator and found that the application fares very well in determining the angle of angulation. We took a total of readings with the angulation of head end of bed varying from 20 to 70 degrees and found that readings by the two methods varied by less than \pm

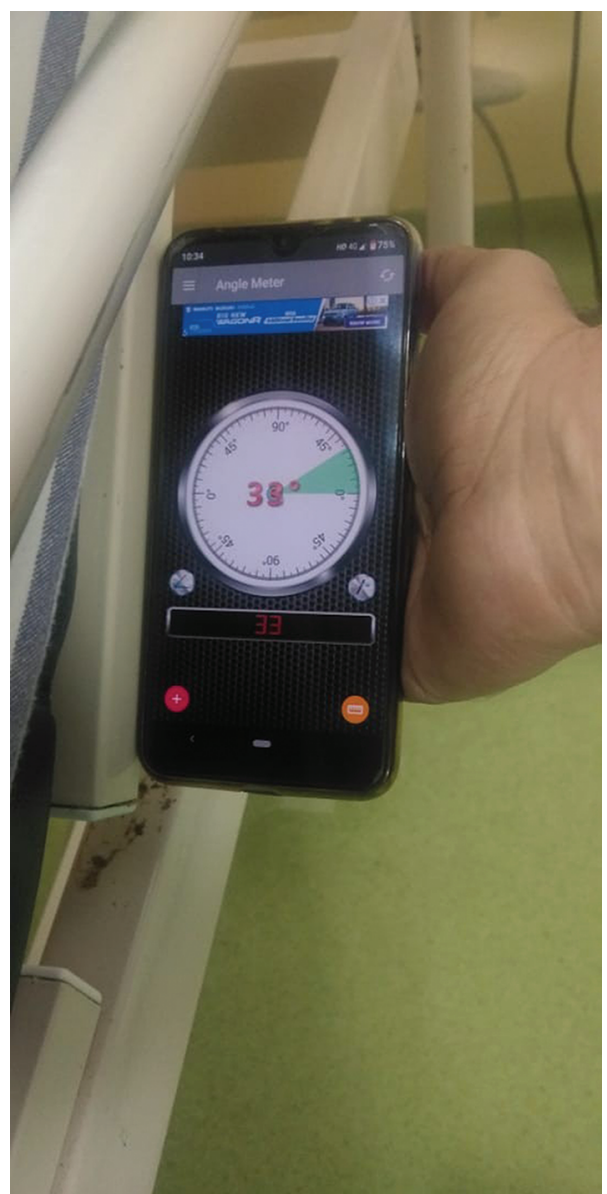

Fig. 2 Angle Meter application demonstrating angulation of head end of intensive care unit bed (33 degrees).

5 degrees on all occasions. Further research in this field may provide us with more definitive evidence on the topic.

\section{Conflict of Interest}

None declared.

\section{References}

1 Torres A, Serra-Batlles J, Ros E, et al. Pulmonary aspiration of gastric contents in patients receiving mechanical ventilation: the effect of body position. Ann Intern Med 1992;116(7):540-543

2 Jadot L, Huyghens L, De Jaeger A, et al. Impact of a VAP bundle in Belgian intensive care units. Ann Intensive Care 2018;8(1):65

3 Rello J, Lorente C, Bodí M, Diaz E, Ricart M, Kollef MH. Why do physicians not follow evidence-based guidelines for preventing ventilator-associated pneumonia?: a survey based on the opinions of an international panel of intensivists. Chest 2002;122(2):656-661

4 Reeve BK, Cook DJ. Semirecumbency among mechanically ventilated ICU patients: a multicenter observational study. Clin Intensive Care 1999;10:241-244 